\title{
Indirect calorimetry in man: a critique of practical problems
}

\author{
By J. V. G. A. Durnin, Institute of Physiology, University of Glasgow, Glasgow \\ GI2 $8 Q Q$
}

I feel honoured to have been asked to give this presentation and I am especially delighted in the particular topic. I well remember Cathcart, who used to be the Professor of Physiology in my department in Glasgow, proudly recounting his scientific lineage which he traced back through Rubner, Voit, Liebig and Laplace to Lavoisier himself. Since Cathcart had as his colleagues, Boyd-Orr and Cuthbertson, and was succeeded by Garry, I feel that I occupy a small part in a most distinguished tradition.

Just over 4 years ago, a short letter by Durnin, Edholm, Miller \& Waterlow (1973) appeared in Nature under the title of 'How much food does man require'. The contents of the letter must have struck some chord of response in large numbers of people because, not satisfied with reading the letter, I received several hundred requests for reprints. I like to think that perhaps the final few sentences were those considered most important. They were: 'We would stress that to determine man's energy need with more precision should be regarded as a major and urgent task. If a calorimeter suitable for man was available it would be possible to calibrate the various ways by which food intake, energy expenditure and energy balance are assessed. Calorimeters for domestic animals have been constructed, but none suitable for man exists today. This work would not be easy or cheap, but we suggest the social and political advantages of obtaining accurate answers could be immense'.

The implications of these statements in relation to our present symposium should be clear. Human calorimetry, in one or more of its techniques, is critical to the assessment of the dietary energy needs of man. How much food we need is primarily a reflection of how much energy we use. Food is eaten for energy-not for trace elements, or vitamins or even for protein-and, in general, if we eat enough food to satisfy our energy requirements we will almost always also satisfy all our other nutritional requirements. That is not meant to be a statement of a universal truth, but it could usefully be looked upon as approximating to a truth of general applicability, and it is frequently overlooked. I know well that it is possible for someone on an adequate energy intake to be deficient in one or more of the nutrients, but this is a situation which is uncommon in practical situations. The energy available in a diet is usually the primary consideration.

Therefore, when food policy is being planned it seems to me essential to have as accurate as possible an assessment of the energy needs of the population. As we tried to point out in that letter to Nature, we do not believe that the energy 
requirements of man are at all well known: apparently comparable individuals may have widely differing energy intakes, some individuals appear to be healthy, physically well-built and active on intakes which would, by current standards, be regarded as inadequate, some fat people do not lose weight on low dietary intakes. The answer to these problems requires an extension and a refinement of our present work with human calorimeters. This whole area of nutritional research is one which, I am convinced, should have one of the highest priorities for research financing. Sadly, in spite of the lip-service paid by the Medical Research Council to the support of research in human nutrition, little money seems to be disbursed to help in solving the big nutritional problems.

Having put forward my view of the general nutritional, economic and indeed political significance of human calorimetry, let me now examine some of the various techniques. I do not intend to deal in any depth with direct calorimetry, nor with the many fascinating historical and analytical aspects of direct and indirect calorimetry; other speakers at this symposium will be referring to various parts of this subject. I am not going to analyse in detail all of the various techniques of direct and indirect calorimetry: they are now too diverse and too numerous to criticize in the time available to me. However, and this is an important point common to many of them, they involve a moderate amount of electronic equipment, and without skilled and frequent electronic servicing the results obtained may be considerably in error. One of the instruments for indirect respiration calorimetry, the Integrated Motor Pneumotachograph (IMP) designed by Wolff (1958) is a useful example of what I mean. On paper it looked excellent. Used by Wolff $I$ am sure it produced reliable results most of the time. In the hands of anyone else-and many of these instruments were sold and used in various parts of the world-the instrument required so much highly-skilled electronic back-up that 1 would be very dubious about believing that most of the results obtained by its use were at all reliable. It has been off the market now for some years.

Indeed, one of the great problems besetting us in the interpretation of our own and of other workers' results is the degree of reliability which we may assign to any particular experiment. The errors are of two different kinds. First, there are the theoretical errors implicit in the techniques, which have been analysed in some detail by our Chairman (Blaxter, 1971) with special reference to farm animals, and by Garrow (1974) on man. I shall be returning to Garrow's analysis later because I do not think he has it all quite right: we have relatively minor disagreements but some of them may be significant.

The second type of error is concerned with the use of the particular equipment or technique, and it is in this sphere that I feel sure most of the trouble occurs. Instrumental error may have a possible theoretical value of $\pm 2 \%$ : in practice, this error may vary from $2 \%$ to $20 \%$ depending upon who is using the instrument, how much background information and experience he has had, how well he cares for and calibrates the equipment, and how much effort he is prepared to exert in ensuring maximum co-operation from his human subjects. When we read the 
results of calorimetric studies, especially those done in field conditions, there is often difficulty in judging the results, in the light of the critical factors I have just mentioned. We can often make some deductions by a careful reading of the 'Methods' section of the paper. But we are sometimes left uncertain about whether or not we can reasonably accept some published results in this area of research. I do not want to sound unjustifiably critical or pompous or bumptious but I have the impression that standards of scientific accuracy are not as high in some areas of human nutrition as they are, in my experience, generally in physiology and in biochemistry. My impression is strongly that most academic physiologists and biochemists would take much more care of their instruments and would calibrate them more frequently than would be the norm in the equivalent nutritional laboratory. This would not matter too much if the instruments were sturdy, dependable, accurate, and could be used without very much skill or critical awareness on the part of the observer. Unfortunately this is often not the case.

I can illustrate these problems by two examples. The first is strictly not directly concerned with calorimetry, but the accuracy with which dietary energy intake is measured is certainly of importance in energy balance studies. Southgate and I (Southgate \& Durnin, 1970), in a very carefully controlled experiment on a group of twelve young men, found less than a $2 \%$ difference in the energy value of their diet, (I) calculated from food tables and (2) measured by bomb calorimetry on the total food homogenate and the excretions of urine and faeces. Yet I am sure that measuring food intake by the same technique as we employed can produce errors of not $2 \%$ but of 5 to ro times that degree, if weighing techniques, sampling, and description of the foodstuffs are not meticulously accurate.

The second example relates to the assessment of energy expenditure from heart rates. There is now a considerable volume of literature on this subject, much of it at variance both with basic physiological knowledge and with our own experience and that of many other workers. The theory is very attractive to those of us who have been searching for years, in this age of micro-instruments, for some sociallyacceptable method of measuring energy expenditure in man in ordinary every-day conditions. In any individual there is a relationship between heart rate and oxygen consumption and if this relationship were stable then the heart rate would allow us to extrapolate to energy expenditure. However, it has been known quantitatively for at least 60 years or so, that this relationship varies considerably between individuals. And even if a regression can be established for any one particular individual, this will vary by reason of several independent factors: physical activity involving the use of large muscle groups, as in walking or moving the whole body, differs in its effect on heart rate and energy expenditure from activity with smaller muscular movements as in using one or both arms; meals, drinks (tea, coffee or alcohol), smoking, body temperature, environment and emotion all exert variable influences. Emotion alone can easily increase heart rate from the average resting level of 80 beats or so/min up to 140 or 150 beats $/ \mathrm{min}$.

A perhaps oversimplified example of the difficulty of discriminating between different situations from the use of heart rate can be shown by one mostly 
sedentary individual spending his $\mathrm{I} 6 \mathrm{~h}$ awake in an average day with a mean heart rate of 90 beats/minute, giving a total heart rate of $16 \times 60 \times 90(86400$ beats in the I6 h) contrasted with another similar individual who, during the lunch break, played half-an-hour's squash at a heart rate of 170 beats $/ \mathrm{min}$. This would mean a difference of $30 \times 80$ (i.e. $170-90$ ) $=2400$ beats and if he went out for half-an-hour's brisk walking in the evening with a heart rate of 120 beats $/ \mathrm{min}$ this would add a further $30 \times 30$ (i.e. $120-90$ ) $=900$ beats to the previous total. The difference between the 16-h day with no physical activity and one with a significant amount of hard exercise is a difference between 86400 and 89700 beats, a relatively small amount which could easily be completely obscured by normal variability. The difference in energy expenditure, on the other hand, would be about I. 5 MJ or 400 or so $\mathrm{kcal} / \mathrm{d}$.

I know of no-one who has tried to use heart rate as a measure of energy expenditure, in a reasonably critical fashion over a long-enough period to extend beyond the euphoric initial phases, who still believes that the technique is capable of providing useful quantitative information on energy expenditure.

I have spent some time on these technical problems because I think they are at the root of much of the uncertainty about our information on energy balance. In my own investigations I have the greatest difficulty in explaining the discrepancy between energy intake and energy expenditure in some of our populations. In our studies in New Guinea (Norgan, Ferro-Luzzi \& Durnin, 1974), the same experienced observers carried out energy-balance studies in an identical fashion on a coastal and on a highland group of people. There was very close agreement between the measured total daily energy expenditure and energy intake of the highland men and women. Yet in the case of both the men and the women living in the coastal region our measured energy intake was about $2 \mathrm{MJ}(500 \mathrm{kcal}) / \mathrm{d}$ less than the measured energy expenditure. In our strictly controlled study in a metabolic unit on ten Ethiopian men in the Nutrition Institute in Addis Ababa during $28 \mathrm{~d}$ (Durnin, 1978), we obtained excellent energy balance assessments on all except two men who again had about $2 \mathrm{MJ}(500 \mathrm{kcal}) / \mathrm{d}$ difference between intake and expenditure. Were all of these discrepancies due to technical faults? They presumably might have been but we are quite unable to see how these might have occurred. Or might there be some error we have not yet properly examined in the calculation of total daily energy expenditure using measurements by indirect calorimetry which are usually carried out during a period of only a few minutes? I do not think this technique in man has ever been completely validated because the classical experiments, particularly the wonderfully conducted studies of Atwater and Benedict, were concerned to show only the very good agreement between direct and indirect calorimetry over periods of many hours.

We have carried out some studies ourselves on exactly this problem in collaboration first of all with John Brockway in the gradient-layer calorimeter built for studies on pigs in the Rowett Research Institute in Aberdeen and subsequently with the late James Findlay and with John Maclean in the gradient layer calorimeter for cows at the Hannah Dairy Research Institute in Ayr. In these 


\section{Vol. 37 The application of human and animal calorimetry}

experiments, we measured oxygen consumption for short periods using Douglas bags or Max Planck Respirometers inside the calorimeter while simultaneously measuring heat output. We did this several times on a total of about ten subjects and, although the experiments were complicated ( 1 ) by problems of heat storage, (2) the long periods required to obtain states of equilibrium in the heat output measurement both while the subject was resting and exercising, and other difficulties, there were several occasions when the two sets of measurements disagreed very considerably: by up to $14 \%$.

These results suggest, therefore, the possibility of a theoretical error between short-term $\mathrm{O}_{2}$ consumption measurements and their extrapolation to energy expenditure. One of the sources of this error, perhaps particularly relevant to shortduration measurements, related to the calculation of energy expenditure using either the classical respiratory quotient (RQ) method of Zuntz \& Schumburg (rgor) or the more commonly-used method of Weir (r949). In both of these methods, if hyperventilation occurs-which may not be uncommon in brief measurements of $\mathrm{O}_{2}$ consumption especially in field conditions-and the RQ is greater than I, an overestimate of energy expenditure of at least $7 \%$ may occur. Indeed, both of these methods of calculation require that the measured $R Q$ actually represents the relative production and consumption of $\mathrm{CO}_{2}$ and $\mathrm{O}_{2}$ in the tissues at the time of the measurement. Anyone with wide experience of these experimental measurements on a variety of human subjects must be well aware of the uncertainty attached to any RQ measured over 5 , 10 or $15 \mathrm{~min}$. Even when the RQ appears well within the normal range, i.e. around 0.80 or 0.85 , it may still not represent the actual $R Q$ in the tissues and, of course, if Weir's method is being employed and only $\mathrm{O}_{2}$ in expired air and pulmonary ventilation are being monitored, there will be no information at all on $R Q$ so the possible error will be completely unknown.

However, a consideration of the cumulative effect of all the possible theoretical sources of error, that is, those divorced from errors resulting from faulty use of faulty equipment, make those theoretical errors unlikely to be able to explain all of the discrepancies that we have found in our New Guinean and Ethopian experiments. I think these cumulative errors may be much higher than the $2 \%$ 'instrumental accuracy of energy metabolism work' which Blaxter (1950), many years ago, suggested as the likely figure; we feel it might be, on occasions, $10-12 \%$, but it is still insufficient as an explanation.

The inescapable conclusion would seem to be that the techniques themselves, even in careful hands, are incapable of satisfactory accuracy. I think this would be the strong impression conveyed by Garrow (1974) in his book on 'Obesity and Energy Balance in Man'. Garrow is very guarded in his critique of the use of the Douglas Bag and the Max-Planck Respirometer and, of course, he has a certain amount of justification for his implied distrust of these techniques. They are by no means ideal methods to use in the measurement of $\mathrm{O}_{2}$ consumption on inexperienced subjects in field conditions. On the other hand, I do not think that it is entirely reasonable to dismiss rather peremptorily methods which have been 
used by the most careful and critical physiologists on thousands of men and women, of a great variety of ages, in dozens of countries in the world. It is fashionable for nutritionists to decry these techniques, but I feel they ought to have some respect for those of us who have utilized such methods for many years with an acute awareness of the problems attached to the potential inadequacy of the equipment. The most critical views of field methods are often held by people with very limited personal experience of their use.

Garrow has also some scathing comments to make about the 'activity diary' method of obtaining timed-records of all the different activities which make up the average day of our experimental subjects. He states that this technique depends upon two assumptions: ( $\mathrm{I}$ ) that the energy cost of measuring an activity for a period of less than $15 \mathrm{~min}$ is representative of the cost of that activity, whatever its duration and whatever the time of day at which it occurs; and (2) that the time spent in each activity during the day is not significantly altered by having to keep the record. He says that 'probably no one would claim that either assumption was entirely true'. I would argue that no-one who has used the activity diary technique widely would even make these assumptions. Certainly I should never dream of suggesting that one measurement of an activity during a few minutes represented more than a rather forlorn hope that it approximated to the average energy cost of that activity. Indeed, Garrow's suggestion belittles the intelligence of a research worker employing such techniques. What is done in practice can be illustrated again by our studies in New Guinea, although there is little difference between these and our measurements on middle-aged Scottish farm workers, forestry workers, office clerks or coal miners. In New Guinea we spent almost all of several consecutive days with our subjects. As only field workers will know, this is much less disruptive than it appears since, after a few hours, subjects soon come to ignore a sympathetic unobtrusive observer: he becomes a relatively neutral part of the environment. When measurements are made of an activity, we already have some knowledge of the normal pattern of such activities and how variable they are, and several measurements would be carried out on each important activity with a view to covering this variability. The mean of these selected measurements seems unlikely, to me, to be very far removed from their true metabolic cost.

Similarly, Garrow's criticism that keeping the activity diary seriously interferes with the normal pattern of the subject is one which is difficult to refute, but which, based on evidence from such diaries kept by more than 2000 individuals, I do not accept. Few subjects complain of this supposedly onerous task: the complainers usually do not volunteer for the experiment, which introduces another, but different, error! The time and effort required to keep these diaries, if the instruction is adequate and checking is frequent, is quite small: a few extra minutes in the day. We have also tried objective tests on the validity and accuracy of these records on a study of some men working in Singer's factory in Clydebank. These men were watched for $2 \mathrm{~d}$, without their knowledge, and the activity records obtained were compared to their own diary recordings. While the duration of each short period of each activity was not always compatible with the independent record, the total 
time spent over the working period of each activity was not significantly different between the records of the subject and of the observer.

Nevertheless, in spite of all my advocacy of the practicability of measuring energy expenditure with acceptable accuracy by indirect calorimetry, I have no doubts about the unproven nature of my case, nor of the entirely justified scepticism of a cynical Garrow-like critic. When we examined the large differences between our measured energy intakes and energy expenditures of the New Guinean coastal populations, in a vain attempt to look for an explanation my colleagues and I were driven to the last and heinous resort of the good scientist: we thought about re-calculating our results ('fiddling' some people might call it). We examined carefully each time record and each energy expenditure measurement and tried reducing them to the limits of conceivable possibility. It made no great difference, there was still a gap of more than $1000 \mathrm{~kJ}$ or several hundred kcal. So we left the results in their original form, with quite considerable relief, I may say. However, the conundrum remained. It will not be solved easily and, it seems to me, only with the help of a sufficiently large and sophisticated direct calorimeter. This may do nothing more than confirm that such discrepancies as we have found are entirely due to methodological faults, but at least we will be one step forward on what is surely a vital path. In many areas of energy requirements we need to have some reasonably accurate way of measuring energy expenditure. I can cite one which I regard as of the highest importance and on which, if I had any faith in either the Medical Research Council or any other similar body having a sympathetic ear, I should immediately submit an application for a research grant. This has to do with the supposed extra energy needs of pregnancy and lactation. At present, these physiological states are regarded, in tables of energy requirements, as needing between approximately I and $2 \mathrm{MJ}$ (about 300 to $500 \mathrm{kcal}$ ) of daily extra energy in the food. Very little evidence exists in practice in support of these extra needs. We have some evidence that there is a very considerable compensatory reduction in physical activity by both the pregnant and the lactating woman, which may almost negate the supposed increased energy requirements. Surely, this is a field where accurate assessments of energy expenditure are necessary.

In this, as in other similar areas, I feel we will progress only if we try both to increase markedly our knowledge by using current techniques in the best possible scientific fashion, and also to marry the advantages and cross-information obtainable from both direct and indirect calorimetry.

\section{REFERENCES}

Blaxter, K. L. (1950). ARC Rep. Ser. no. I 668.

Blaxter, K. L. (1971). Fedn Proc. Fedn Am Socs. exp. Biol. 30, 1436.

Durnin, J. V. G. A., Edholm, O. G., Miller, D. S. \& Waterlow, J. C. (1973). Nature, Lond. 242, 418.

Durnin, J. V. G. A. (1978). Nutritio Dieta. (In the Press.)

Garrow, J. S. (1974). Energy Balance and Obesity in Man. London: North-Holland Publishing Co. 
Norgan, N., Ferro-Luzzi, A. \& Durnin, J. V. G. A. (1974). Phil. Trans. R. Soc. B. 268, 309. Southgate, D. A. T. \& Durnin, J. V. G. A. (1970). Br. F. Nutr. 24, 517.

Weir, J. B. deV. (1949). F. Physiol., Lond ro9, 1.

Wolff, H. S. (1958). Quart. Fl exp. Physiol. 43, 270.

Zuntz \& Schumberg (1901). Studien zur einer Physiologie des Marsches. Berlin. 